\title{
Suplementação de vitamina C na estruturação do tecido conjuntivo de melanotênia-maçã $\tilde{a}^{1}$
}

\author{
Ive S. Muzitano ${ }^{2}$, Clovis A. Neves ${ }^{3}$, Marcella C. Radael ${ }^{4 *}$, Fabrício P. Rezende ${ }^{5}$, Pedro P. \\ Mendonça ${ }^{6}$, Monique V.B. dos Santos ${ }^{7}$, Dalcio R. de Andrade ${ }^{4}$ e Manuel V. Vidal Junior ${ }^{4}$
}

\begin{abstract}
Muzitano I.S., Neves C.A., Radael M.C., Rezende F.P., Mendonça P.P., Santos M.V.B., Andrade D.R. \& Vidal Junior M.V. 2014. [Vitamin C supplementation in the structuring of connective tissue of red rainbowfish.] Suplementação de vitamina C na estruturação do tecido conjuntivo de melanotênia-maçã. Pesquisa Veterinária Brasileira 34(8):780-784. Setor de Aquicultura, Laboratório de Zootecnia e Nutrição Animal, Universidade Estadual do Norte Fluminense Darcy Ribeiro, Av. Alberto Lamego 2000, Parque Califórnia, Campos dos Goytacazes, RJ 28013-620, Brazil. E-mail: marcellaradael@yahoo.com.br

Farmed fishes are highly sensitive to diets deficient in ascorbic acid with clinical symptoms that affect performance and commercialization for causing deformities. Aiming to meet the minimum levels for red rainbow fish, six isoaminoacid and isocaloric diets with varying levels of active vitamin $\mathrm{C}$ were tested. At the end of 42 days experimental period, 36 fishes were histologically analyzed for the percentage of connective tissue and muscle fibers in order to determine the influence of the Vitamin C percentage in those ratios. Although the averages are statistically indistinguishable from the quantitative point of view, qualitatively higher levels of vitamin $\mathrm{C}$ allow better tissue structure. The breakdown of muscle tissue is indicative for dietary deficiency of ascorbic acid.
\end{abstract}

INDEX TERMS: Ascorbic acid, Glossolepis incisus, ornamental fish, fish farming, collagen.

RESUMO.- Peixes cultivados mostram-se altamente sensíveis a dietas deficientes em ácido ascórbico com sinais clínicos que afetam o desempenho e a comercialização por provocar deformidades. Com objetivo de conhecer os níveis mínimos para a melanotênia-maçã, foram testadas seis rações isoaminoacídicas e isocalóricas com níveis variados de vitamina $\mathrm{C}$ ativa. Ao final dos 42 dias experimentais, 36

\footnotetext{
${ }^{1}$ Recebido em 23 de dezembro de 2013.

Aceito para publicação em 4 de julho de 2014.

${ }^{2}$ Escritório Regional do Médio Paraíba (FIPERJ), RJ-145 Km 96 no. 56660, Rio das Flores, RJ 27660-000, Brasil.

${ }^{3}$ Departamento de Biologia Geral, Centro de Ciências Biológicas e da Saúde, Universidade Federal de Viçosa (UFV), Rua P.H. Rolfs s/n, Viçosa, MG 36570-000, Brasil.

${ }^{4}$ Universidade Estadual do Norte Fluminense Darcy Ribeiro, CCTA/ LZNA, Sala 112, Avenida Alberto Lamego 2000, Parque Califórnia, Campos dos Goytacazes, RJ 28013-620, Brasil. *Autor para correspondência: marcellaradael@yahoo.com.br

${ }^{5}$ Embrapa Pesca e Aquicultura, Quadra 104 Sul, Av. Lo 1, Norte 34, Conj.4, Bairro Plano Diretor Sul, Palmas, TO 77020-020, Brasil.

${ }^{6}$ Instituto Federal de Educação, Ciência e Tecnologia do Espírito Santo (IFES), Campus de Alegre, Rodovia Cachoeiro-Alegre Km 48, Cx. Postal 47, Distrito de Rive, Alegre, ES 29520-000, Brasil.

${ }^{7}$ Instituto Federal de Educação, Ciência e Tecnologia de Mato Grosso, Avenida dos Ramires s/n, Parque Industrial, Caceres, MT 78200-000, Brasil.
}

peixes foram analisados histologicamente quanto à porcentagem de tecido conjuntivo e fibras musculares a fim de determinar a influência da porcentagem de Vitamina $C$ nesses índices. Apesar de as médias serem estatisticamente iguais do ponto de vista quantitativo, qualitativamente os níveis mais altos de vitamina $C$ possibilitaram melhor estrutura tecidual. A desestruturação do tecido muscular é um indicativo da deficiência alimentar com ácido ascórbico.

TERMOS DE INDEXAÇÃO: Ácido ascórbico, Glossolepis incisus, peixe ornamental, piscicultura, colágeno.

\section{INTRODUÇÃO}

A piscicultura ornamental no Brasil surgiu na década de 1970, cerca de trinta anos depois da piscicultura de corte, e hoje é um agronegócio que envolve alguns milhares de produtores. A falta de rações, específicas, para a produção de peixes ornamentais, é uma das consequências da escassez de estudos de exigências nutricionais para as diferentes espécies cultivadas. Este entrave é global, sendo defrontado corriqueiramente pelos piscicultores, comerciantes e aquaristas que são os principais consumidores de peixes ornamentais.

Faz-se necessário, portanto, o desenvolvimento de ra- 
ções e técnicas de manejo eficientes na nutrição e redução do estresse, visando melhorar a qualidade do peixe produzido no Brasil. Rações mais eficientes são uma demanda constante e necessária para a piscicultura ornamental em nível mundial, que somada a oferta competitiva de peixes oriunda do extrativismo, representam consequente agregação de preços e melhoria da renda, principalmente para os piscicultores familiares.

Umas das espécies que desperta atenção dos produtores, atualmente, é Glossolepis incisus, conhecida popularmente como melanotênia-maçã. É oriunda da Austrália e Nova Guiné. Possui características morfológicas peculiares, como a coloração vermelho tomate bem acentuada dos machos, o que contribui na agregação de valor na comercialização. Suas características reprodutivas já foram descritas (Vidal Júnior, 2005), porém, pouco se sabe em relação às suas exigências nutricionais.

O ácido ascórbico (vitamina C) é conhecido como promotor de numerosos processos bioquímicos e fisiológicos, tanto em animais como em plantas (O'Keefe 2001). A vitamina $C$ contribui para a formação do tecido ósseo e cartilaginoso é responsável por melhoras no crescimento de peixes e sua deficiência provoca deformações ósseas, hemorragias, anorexia e baixa resistência ao estresse (Wang et al. 2003). 0 ácido ascórbico é cofator de reações de hidroxilação da prolina, necessária para a formação do colágeno nos tecidos (Gonçalves \& Maia Campos 2006). Sendo, portanto, fundamental na formação da matriz conjuntiva, óssea e cartilaginosa; bem como na cicatrização de feridas. Este ácido participa ainda da síntese de corticosteróides e de carnitina, além de facilitar a absorção de ferro (Rotta 2003). Além disso, devido ao alto poder redutor, a vitamina $C$ pode participar na prevenção da oxidação de lipídios na dieta e nos tecidos, em ação sinérgica com a vitamina $\mathrm{E}$ (Halver 2002).

A vitamina $C$ atua, também, em várias reações de hidroxilação como, por exemplo, nas hidroxilação de lisina e prolina no pró-colágeno, necessárias para as ligações cruzadas entre as fibrilas de colágeno (Rucker \& Morris 1997). 0 colágeno, presente no tecido conjuntivo, contém altos níveis de hidroxiprolina, que é formada pela ação da prolina-lisil hidroxilase sobre os aminoácidos prolina e lisina, e têm como cofatores de hidroxilação o ferro, o alfa-cetoglutarato e a vitamina C. Por esta razão, o ácido ascórbico é importante na manutenção do tecido conjuntivo normal e na cicatrização, onde o tecido conjuntivo é o primeiro a proliferar. A vitamina $\mathrm{C}$ é rapidamente absorvida pelas células onde há intensa formação de colágeno, como tegumento, cartilagens e ossos (Halver 1972). Os peixes não apresentam a enzima L-gulonolactona oxidase e, portanto, não sintetizam a vitamina $C$ necessitando de sua suplementação na dieta (Neu 2010). É considerada também como uma das vitaminas essenciais para os peixes (Ai et al., 2006), devido ao fato de que a maioria dos teleósteos não possui a capacidade de sintetizar essa vitamina em suas vias metabólicas (Darias et al. 2011).

Peixes cultivados têm se mostrado altamente sensíveis a dietas deficientes em ácido ascórbico (Lavens et al. 1995). Muitos sinais, como crescimento reduzido, perda de apetite, conversão alimentar prejudicada, deformidades esqueléticas, em especial na coluna (Stedman 1996), deformidades no opérculo e nas cartilagens das brânquias, anemia, hemorragia de vários órgãos, demora ou diminuição da cicatrização de feridas, coloração escura, redução do desempenho reprodutivo e diminuição da eclodibilidade têm sido encontrado em peixes que consomem dietas deficientes nesta vitamina (Rotta 2003, Lovell 1989). Peixes alimentados com ácido ascórbico marcado radioativamente com C14 mostraram que esta vitamina é rapidamente absorvida pelas áreas onde o colágeno é formado, isto é, na pele, na nadadeira caudal, nas cartilagens da cabeça e do maxilar, nas cartilagens que suportam as brânquias e nos ossos (Halver 1972).

Esse estudo foi realizado com o intuito de avaliar os efeitos causados pela suplementação de rações com níveis crescentes de vitamina $C$ na estruturação do tecido conjuntivo de melanotênia-maçã, através da análise histológica de tecido do pedúnculo caudal.

\section{MATERIAL E MÉTODOS}

Foram utilizados 216 juvenis, não sexados, de Glossolepis incisus, com mesma idade e similaridade de peso e comprimento, provenientes do Setor de Aquicultura da UENF localizado na Unidade de Apoio à Pesquisa em Zootecnia em Campos dos Goytacazes, RJ. 0 experimento teve duração de 42 dias.

Os peixes foram distribuídos em lotes de 12 animais em cada um dos 18 aquários experimentais de 40 litros de volume útil, que estavam interligados em mesmo sistema de recirculação de água com bombas de aspiração submersas e caixas com biofiltros.

Cada aquário foi considerado uma unidade experimental. Foram utilizadas seis dietas experimentais (tratamentos) isoaminoacídicas (29,9\% de PB) e isocalóricas (3.101 kcal de ED/kg), formuladas com os mesmos ingredientes (Quadro 1) e diferenciadas pelos níveis equidistantes de vitamina C estabilizada (Lutavit $\mathrm{C}^{\circledR}$ Aquastab, com $42 \%$ de atividade). Os tratamentos foram constituídos por $0,150,300,450,600$ ou $750 \mathrm{mg}$ de vitamina $\mathrm{C}$ ativa por quilo de ração, com três repetições cada, em um delineamento inteiramente casualizado. Para inclusão da vitamina $C$, a ração controle possuía $3 \mathrm{~g}$ de celulose/kg de ração. A Vitamina $\mathrm{C}$ foi adicionada em substituição a este inerte.

A ração foi administrada duas vezes ao dia (9h e 17h) ad libitum. Ao final do experimento, foram coletados dois peixes sexados (um macho e uma fêmea) de cada unidade experimental, totalizando 36 peixes para coleta de amostras de pedúnculo caudal. Avaliou-se, também, um lote de oito peixes abatidos no início do experimento, visando representar a condição inicial dos peixes.

Estes espécimes, após serem anestesiados e eutanasiados, foram fixados inteiros, durante 24 horas, e posteriormente preservados em álcool etílico a 70\%. Foram utilizados dois tipos de fixadores em diferentes amostras, o fixador de Stefanini (Stefanini et. al. 1967), e a formalina de Carson (Carson et al. 1973), de forma que a metade dos peixes amostrados fosse fixada em um fixador e a outra metade em outro.

Os animais foram seccionados transversalmente na altura da inserção da cauda (Fig.1) Os pedúnculos caudais foram desidratados em séries crescentes de álcool etílico (80\%, 90\%, 95\% e $100 \%$ ) em passagens de 30 minutos. A inclusão foi realizada em resina histológica (Historesin-Leica ${ }^{\circledR}$ ).

Cortes transversais de $3 \mu \mathrm{m}$ de espessura foram obtidos em micrótomo rotatório (RM2155, Leica) com navalhas de vidro. As lâminas foram coradas com o corante Tricromico de Cason (Gray 
Quadro 1. Ingredientes e composição da ração

\begin{tabular}{lc}
\hline Ingredientes & Valores (\%) \\
\hline Farelo de arroz & 15,00 \\
Milho em grão & 15,02 \\
Farelo de trigo & 16,00 \\
Óleo de soja & 03,00 \\
Farinha de carne e ossos (40\% PB) & 14,00 \\
Farinha de peixe (55\% PB) & 18,59 \\
Farelo de soja (45\% PB) & 18,03 \\
Celulose & 00,15 \\
Calcário calcítico & 00,00 \\
Fosfato bicálcico & 00,00 \\
DL-metionina & 00,00 \\
Lisina & 00,00 \\
BHT & 00,01 \\
Premix* & 00,20 \\
TOTAL (\%) & 100,00 \\
Composição da ração & \\
PB (\%) & 29,90 \\
MS (\%) & 89,59 \\
Gordura (\%) & 9,04 \\
Fibra (\%) & 4,79 \\
Material minera (\%) & 12,72 \\
Cálcio (Ca \%) & 3,23 \\
Fósforo disponível (P \%) & 1,71 \\
Lisina (\%) & 1,70 \\
Metionina (\%) & 0,57 \\
Cisteína (\%) & 0,45 \\
Triptofano (\%) & 0,29 \\
Treonina (\%) & 1,13 \\
Arginina (\%) & 2,09 \\
Relação PB:ED & 10,39 \\
Relação Ca:P & 1,89 \\
\hline Premi vitamina & \\
\hline
\end{tabular}

* Premix: vitaminas A (100.000UI), $\mathrm{D}_{3}$ (32.000UI), E (240mg), $\mathrm{B}_{1}$ (20mg), $B_{2}(61,4 \mathrm{mg}), B_{6}(20 \mathrm{mg}), B_{12}(320 \mathrm{mg}), K_{3}(40 \mathrm{mg})$, ácido fólico (7,2mg), ácido pantotênico (294mg), biotina (1mg). cloreto de colina (2000mg),;niacina (396mg), aminoácido L-lisina (20g), minerais Ca (240mg), P (78mg), Na (60g), Co (3,6mg), Cu (4750mg), Fe (2228mg), I (7,32mg), Mn (27mg), Se (6,6mg), Zn (2603mg), Flúor (780mg), antioxidante $(200 \mathrm{mg})$.

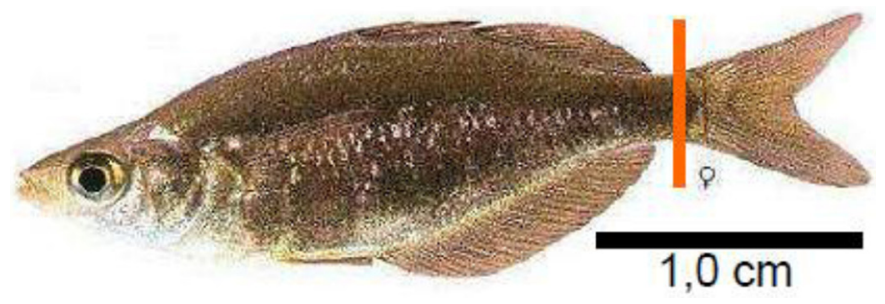

Fig.1. Local do corte transversal - altura do pedúnculo caudal.

1954), e foram analisadas 1.760 imagens, evidenciando as fibras musculares, sendo 1.440 imagens dos tratamentos e o restante em amostras de oito peixes do dia zero de experimento.

Para isto, foram utilizadas imagens obtidas em microscópio óptico (BX 60, Olympus) com câmera digital (Q-Color 3, Olympus) com objetiva de 10x e 40x. As análises realizadas com auxílio do programa Image - Pró Plus, versão 4.5.0.29 (Media Cibernetics).

Com o programa Image-Pro Plus foi criada uma máscara em forma de grade padronizada, com circunferências simétricas de um pixel de diâmetro, sem margens, e espaçamentos de 70 pixels na horizontal e vertical entre os círculos, somando-se em 35 circunferências ortogonais sobrepostas às imagens capturadas.

As circunferências que estavam em sobreposição às fibras musculares em cortes transversais eram contadas em números absolutos, contou-se também, o total absoluto de circunferências existentes no campo visível (sem tecido ósseo, cartilaginoso, fibras musculares em corte longitudinais e capilares).

0 total absoluto de círculos do campo foi subtraído do número de círculos encontrados nas fibras musculares em cortes transversais, encontrando-se o número de circunferências do tecido conjuntivo. Tendo como base o total de círculos como 100\%, encontraram-se as porcentagens de fibras musculares e de tecido conjuntivo do campo, a partir dos seus respectivos números absolutos. Os dados de porcentagem de tecido conjuntivo e fibras musculares foram comparados com os tratamentos propostos. Foi utilizado o programa estatístico SAEG que realizou a análise de variância (ANOVA), teste de comparação de médias t Student, ao nível de 5\% de probabilidade, e correlações de Pearson com o objetivo de estimar o melhor nível de vitamina $\mathrm{C}$ para cada variável analisada.

As análises estatísticas das variáveis foram analisadas segundo o modelo matemático Yik $=\mu+\mathrm{Ti}+\varepsilon i k$. Em que Yik = variável estudada, referente ao tratamento i; $\mu=$ média geral das características; $\mathrm{Ti}=$ efeito dos diferentes níveis de vitamina $\mathrm{C}$, sendo $\mathrm{i}=$ 0 , 150, 300, 450, 600, 750; عik = erro aleatório associado a cada observação.

\section{RESULTADOS E DISCUSSÃO}

A qualidade da água foi monitorada durante todo o experimento, e os valores de temperatura $\left(29,5 \pm 1,2^{\circ} \mathrm{C}\right)$ mantiveram-se dentro da faixa de conforto para o cultivo desta espécie em cativeiro, que é de 29 a $32^{\circ} \mathrm{C}$. $0 \mathrm{pH}$ de $7,9 \pm 0,2$ durante o experimento, também se apresentou próximo daquele indicado para o cultivo de melanotênia-maçã, sendo o valor indicado para a espécie na faixa de 7,0 e 8,0 (Fishbase 2013).

As porcentagens de tecido conjuntivo e de fibra muscular nos cortes histológicos da musculatura da região da inserção da cauda da melanotênia-maçã, não foram influenciadas estatisticamente pelos níveis equidistantes de ácido ascórbico, não possuindo significância pelo teste $\mathrm{t}$ $(\mathrm{P}<0,05)$. Rucker \& Morris (1997) afirmaram que o ácido ascórbico é importante na manutenção do tecido conjuntivo normal e na cicatrização, onde o tecido conjuntivo é o primeiro a proliferar. Wahli et al. (2003) também concluíram que o aumento de vitamina $\mathrm{C}$ na dieta de truta arco-íris influencia no processo de cicatrização pelo aumento da síntese de colágeno que dá origem ao tecido fibroso.

A Figura 2A demonstra uma clara desorganização tecidual no corte histológico no nível zero de vitamina C, quando comparada com a Figura 2D, que traduz o nível $750 \mathrm{mg} /$ kg de ácido ascórbico dos tratamentos. Segundo Rucker \& Morris (1997) lesões que ocorrem nos tecidos conjuntivos são primeiramente um resultado do colágeno sub-hidroxilado (nos resíduos específicos de prolina e lisina), ficando suscetível à degradação de forma anormal, sendo um sinal da hipovitaminose $C$ em peixes.

Os níveis mais baixos de vitamina C (Fig.2A e 2B) de zero e $150 \mathrm{mg} / \mathrm{kg}$, respectivamente, apresentaram uma atrofia das fibras musculares quando comparadas com as Figuras 2C e 2D dos juvenis alimentados com 600 e $750 \mathrm{mg} /$ kg de ácido ascórbico ativo. Fracalossi (1998) fez estudos histológicos no acará-açú e demonstrou que os peixes sem suplementação de vitamina $\mathrm{C}$ apresentaram deformidades na cartilagem de suporte dos filamentos branquiais, como também atrofia nas fibras musculares.

Apesar de quantitativamente as médias serem estatisti- 


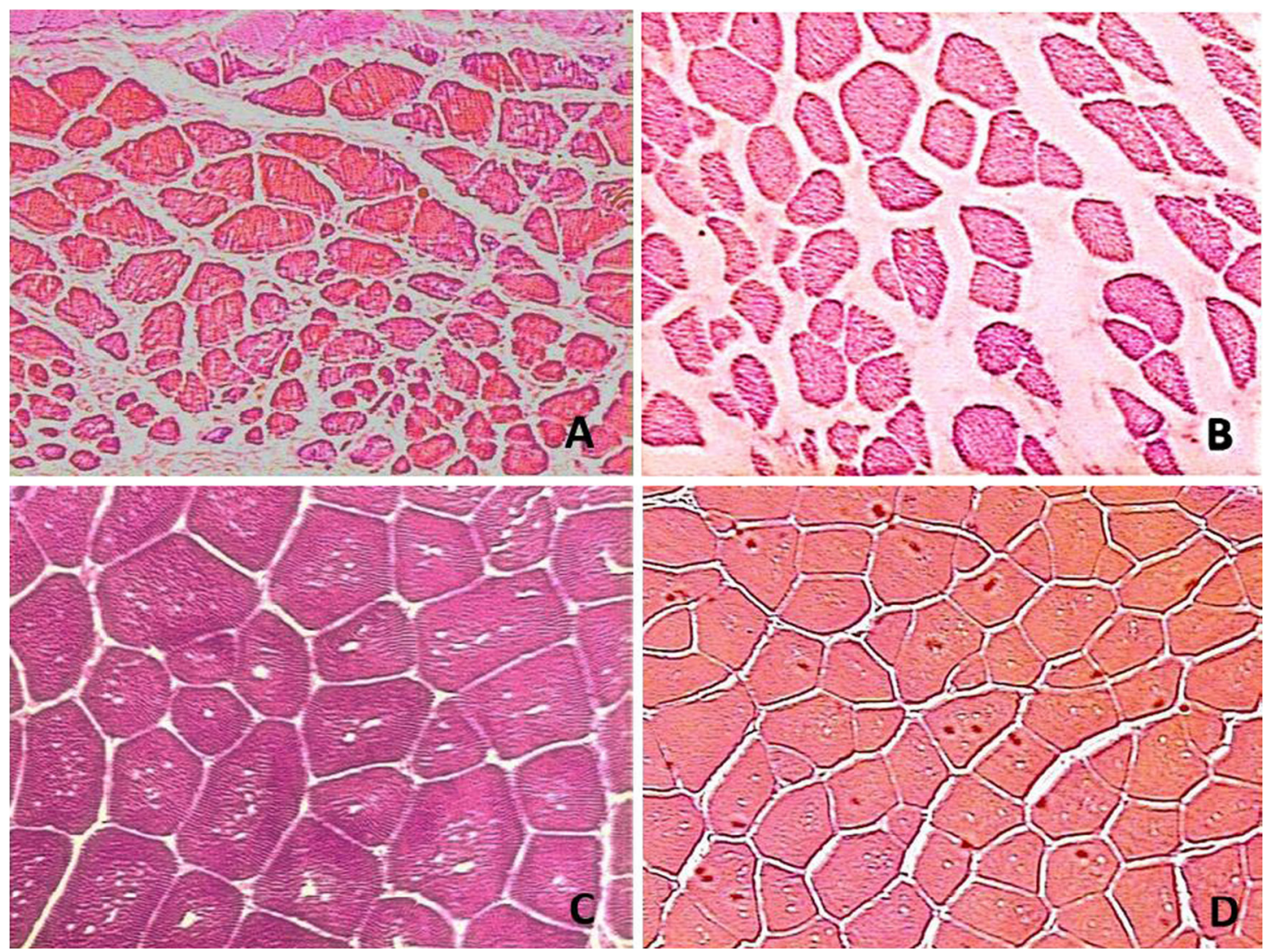

Fig.2. Tecido muscular do pedúnculo caudal de alevinos de melanotênia maçã com diferentes níveis de suplementação de vitamina $C$ na ração. (A) Zero miligramas de vitamina C. (B) 150 miligramas de vitamina C. (C) 600 miligramas de vitamina C. (D) 750 miligramas de vitamina C. Tricrômico de Cason/5 $\mu$ m, obj.40x.

camente iguais, qualitativamente, os níveis mais altos (600 e 750mg de vitamina C/kg de ração), apresentaram melhor estrutura tecidual, nos estudos histológicos de efeito, comparado aos menores níveis (zero e $150 \mathrm{mg}$ de vitamina $\mathrm{C} / \mathrm{kg}$ de ração). 0 que indica que a desestruturação do tecido muscular desses níveis mais baixos pode ser um sinal de deficiência alimentar de ácido ascórbico, mesmo considerando-se a leve retração de tecido observada no tratamento $150 \mathrm{mg} / \mathrm{kg}$ (Fig.2B), possivelmente por diferença no tempo para fixação.

O'Keefe (2001) concluiu que a exigência de ácido ascórbico pelos peixes, como para qualquer outra vitamina, é expressa como a quantidade de atividade vitamínica necessária por quilo de peso vivo por dia para atingir uma resposta fisiológica específica no organismo. Em qualquer nível de resposta, estas exigências são afetadas pelo tamanho do peixe e pelo seu estado fisiológico, como também pelas interações dos nutrientes e fatores ambientais.

Apesar dos níveis de ácido ascórbico não terem apresentado efeito sobre as variáveis analisadas, fêmeas e machos, por apresentarem fisiologias diferenciadas, podem possuir diferentes exigências de vitamina $C$.

Touhata et al. (2000) observaram diferenças, principalmente no período de maturação de gônadas e desova, no volume de colágeno nas trocas sazonais entre fêmeas e machos de sea bream, baseado no conteúdo da forma proteica hidroxiprolina, assim sugerindo que o metabolismo do colágeno também possa ser regulado por fatores endocrinológicos, como hormônios esteroides sexuais.
Ao contrário das fêmeas, os machos apresentaram, com o aumento dos níveis de vitamina $\mathrm{C}$, um aumento da proporção de fibra muscular e redução da proporção de tecido conjuntivo, podendo ser um indicativo de diferenças no metabolismo, em nível tecidual da musculatura, entre fêmeas e machos suplementados com ácido ascórbico.

Outro fator observado foi que durante a coleta dos espécimes, após o esforço de natação para fuga da rede de captura, os animais provenientes dos tratamentos de 0 e $150 \mathrm{mg}$ de vitamina $\mathrm{C}$, passaram a demonstrar uma deformidade da coluna vertebral, fato que não era visível anteriormente. Esse fator sugere, portanto que, caso o experimento tivesse uma duração maior, esses animais poderiam apresentar deformidades que inviabilizariam inclusive, sua comercialização.

\section{CONCLUSÃO}

Rações para melanotênia-maçã devem ser suplementadas com $600 \mathrm{mg}$ de vitamina $\mathrm{C}$ por kg. Níveis de vitamina $\mathrm{C}$ acima de $600 \mathrm{mg} / \mathrm{kg}$ proporcionam melhor estruturação do colágeno em melanotênia-maçã.

Agradecimentos.- À UENF, CAPES e FAPERJ.

\section{REFERÊNCIAS}

AI Q., Mai K., Tan B., Xu W., Zhang W., Ma H. \& Liufu Z. 2006. Effects of dietary vitamin $\mathrm{C}$ on survival, growth, and immunity of large yellow croaker, Pseudosciaena crocea. Aquaculture 261:327-336. 
Carson F.L., Martin J.H. \& Lynn J.A. 1973. Formalin fixation for electron microscopy: a reevaluation. Am. J. Clin. Pathol. 59:365-373.

Darias M.J., Mazurais D., Koumoundouros G., Cahu C.L. \& Zambonino-Infante J.L. 2011. Overview of vitamin D and C requirements in fish and their influence on the skeletal system. Aquaculture 315:49-60.

Fishbase 2013. Glossolepis incises. Disponível em <http://www.fishbase. org/Summary/SpeciesSummary.php?ID=10477\&genusname=Glossole pis\&speciesname $=$ incisus \&AT $=$ glossolepis + incisus\&lang=Portuguese $>$ Acesso em 17 jun. 2013.

Fracalossi D.M. 1998. Doenças nutricionais em peixes. Anais 2º Simpósio sobre Manejo e Nutrição de Peixes, Piracicaba. CBNA, Campinas, p.97-122.

Gonçalves G.M.S. \& Maia Campos P.M.B.G. 2006. Ácido ascórbico e ascorbil fosfato de magnésio na prevenção do envelhecimento cutâneo. Infarma 18(7/8):3-6.

Gray P. 1954. The Microtomist's Formulary and Guide. Originally published by The Blankiston Co., Philadelphia.

Halver J.E. 2002. Fish Nutrition. $3^{\text {rd }}$ ed. School of Aquatic and Fishery Sciences, University of Washington, Seattle, WA, p.99-107.

Halver J.E. 1972. The hole of ascorbic acid in fish disease and tissue repair. Bull. Japn. Soc. Scient. Fisheries 38:79-92.

Lavens P., Sorgeloos P., Dhert P. \& Devresse B. 1995. Larval foods, p.373397. In: Bromage N.R. \& Roberts R.J. (Eds), Broodstock Management and Egg and Larval Quality. Blackwell, Oxford. 424p.

Lovell T. 1989. Nutrition and Feeding of Fish. Van Nostrand Reinhold, New York. 260p.

Neu D.H. 2010. Glicerol na dieta de tilápias do Nilo (Oreochromis niloticus).
Dissertação de Mestrado em Recursos Pesqueiros e Engenharia de Pesca, Universidade Estadual do Oeste do Paraná, Toledo, PR. 59p.

O'Keefe T. 2001. Ascorbic acid and stable ascorbato esters as sources of vitamin C in aquaculture feeds. American United Soybean Board, Soybean Association, Singapure. ASA Tech. Bull. AQ48.

Rotta M.A. 2003. Utilização do Ácido Ascórbico (Vitamina C) pelos Peixes. Doc. 49 (ISSN 1517-1973), Embrapa Pantanal, Corumbá, MS.

Rucker R.B. \& Morris J.G. 1997. The vitamins, p.703-739. In: Kaneko J.J., Harvey J.W. \& Bruss M.L. (Eds), Clinical Bioquimistry of Domestic Animals. $5^{\text {th }}$ ed. Academic Press, San Diego.

Stedman 1996. Dicionário Médico. 25a ed. Guanabara Koogan, Rio de Janeiro. 1657p. (Traduzido por Araújo C.L.C., Vanzellotti,I.R., Lemos J.I. \& Azevedo M.F.)

Stefanini M., De Martino C. \& Zamboni L. 1967. Fixation of ejaculated spermatozoa for electron microscopy. Nature 216(14):173-174.

Touhata K., Tanaka M., Toyohara H., Tanaka H. \& Sakaguchi M. 2000. Seasonal change in collagen content of red sea bream muscle. Fisheries Sci. 66:553-557.

Vidal Júnior M.V. 2005. Melanotênia maçã. Revta Panorama da Aquicultura 15(88):39-42.

Wahli T., Verlhac V., Girling P., Gabaudan J. \& Aebischer C. 2003. Influence of dietary vitamin $\mathrm{C}$ on the wound healing process in rainbow trout (Oncorhynchus mykiss). Aquaculture 225:371-386.

Wang X., Kim K.W., Bai S.C., Huh M.D. \& Cho B.Y. 2003. Effects of the different levels of dietary vitamin $\mathrm{C}$ on growth and tissue ascorbic acid changes in parrot fish (Oplegnathus fasciatus). Aquaculture 215:203-211. 